\title{
Effect of iodine doping on the characteristics of polythiophene thin films prepared by aerosol assisted plasma jet polymerization at atmospheric pressure
}

\author{
Hammad R. Humud, Manal Midhat Abdullah, Dawood Majed Khudhair \\ Department of Physics, College of Science, University of Baghdad \\ E-mail: Manal.madhat@yahoo.com
}

\begin{abstract}
Iodine-doped polythiophene thin films are prepared by aerosol assisted plasma jet polymerization at atmospheric pressure and room temperature. The doping of iodine was carried out in situ by employing iodine crystals in thiophene monomer by weight mixing ratios of $1 \%, 3 \%, 5 \%$ and $7 \%$. The chemical composition analyses of pure and iodine-doped and heat-treated polythiophene thin films are carried out by FTIR spectroscopy studies. The optical band gaps of the films are evaluated from absorption spectrum studies. Direct transition energy gaps are determined from Tauc plots. The structural changes of polythiophene upon doping and the reduction of optical band gap are explained on the basis of the results obtained from FTIR spectroscopy, UV-VIS absorption studies, X-ray diffraction and atomic force microscope (AFM) analysis. The energy band gap will be different according to the concentration of polythiophene iodine. It can be concluded that iodine-doped polythiophene thin films can be prepare by aerosol assisted plasma jet polymerization and control the optical energy band gap regulars by controlling the thiophene -iodine weight mixing ratios.
\end{abstract}

Key words Polythiophene iodine doping, thin films, optical properties, band gap, XRD.

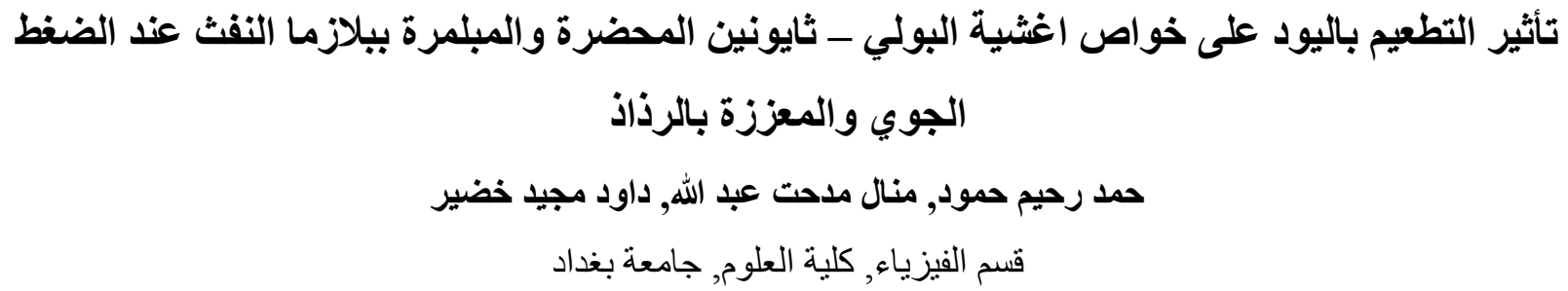

Article info.

Received: Sep. 2014

Accepted: Nov. 2014

Published: Dec. 2014

الخلاصة

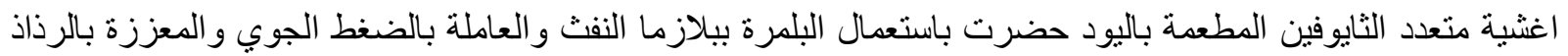

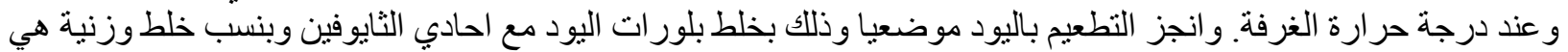

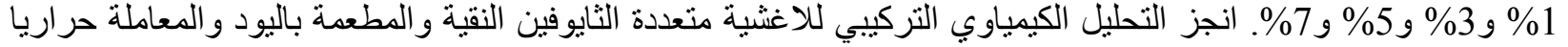

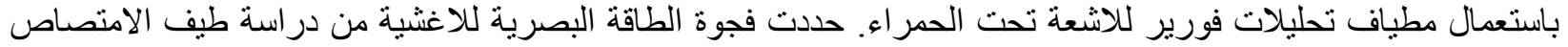

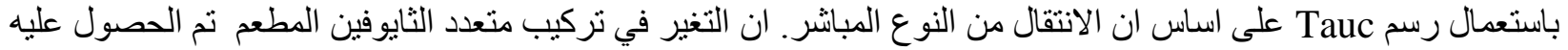

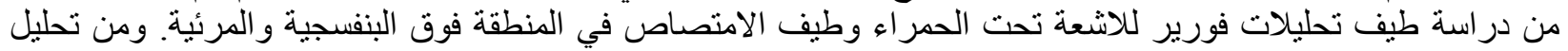

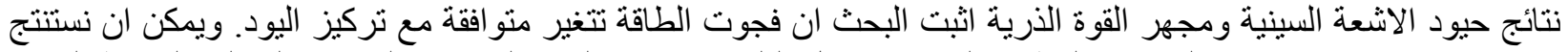

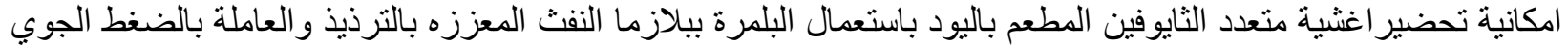
و التحكم المنتظم بفجوة الطاقة البصرية من خلال التحكم في نسبة الخلط الوزني لمزيج الحئ الحادي الثايوفين و اليود. 


\section{Introduction}

The employment of plasma polymerization for synthesis of novel thin film materials has become attractive and has been an active area of research in the past recent-years [1]. Originally this technique was employed to coat passive layers, but the current trend is to extend this technology to other applications as well, in which device performances are influenced by surface compositions. Controllability and reproducibility of the surface composition of plasma polymerized thin films is of most important to achieve superlative performance. It is known that several reaction parameters like power input, monomer flow rate, monomer vapor pressures, substrate temperature and positioning of substrates relative to the plasma torch end influence the structure and composition of plasma polymerized thin films [2,3]. The investigations of the optical properties of polymer thin films have gained attention due to their potential applications in optical sensors, LEDs and as antireflective coatings [4, 5].The effect of doping on the band gap of polythiothene is already dealt with [6,7] but a systematic study on the stability and the structure of the in situ iodine doped thiophene films by aerosol assisted plasma jet polymerization at atmospheric pressure has not been reported. Here, a report the preparation and optical properties of plasma polymerized thiophene thin films. Where the In situ iodine doping is carried out by aerosol assisted plasma jet polymerization at atmospheric pressure and room temperature .To investigate the effects of doping on the optical band gap, UV-VIS studies are carried out to determine the optical band gap and other optical parameters of plasma polymerized thiophene thin films. FTIR studies are carried out to elucidate the effect of doping on the chemical structure of the plasma polymerized thiophene thin films [8].

\section{Experimental work}

Iodine-doped polythiophene thin films have been prepared by aerosol assisted plasma polymerization. Thin films were prepared by dielectric barrier discharge plasma jet a homemade[9]. The thin films were deposited on glass substrates. Pure thiophene monomer was used as the organic precursor. Fig.1 schematic diagram for the non-equilibrium atmospheric pressure plasma Iodine-doped polythiophene thin films praparation. Argon gas with flow rate of of $1 \mathrm{l} / \mathrm{min}$ passes through the nobilizer which contains a mixture of iodine and thiophene with weight mixing ratios of $1 \%$, $3 \%, 5 \%$ and $7 \%$. the mixture convert to aerosol where the Ar gas passes through the mobilizer, this aerosol was guided by the $\mathrm{Ar}$ gas to the plasma torch. the plasma was ignited by using an electric source at a fixed frequency of $28.0 \mathrm{kHz}$. The plasma was generated downstream to the substrate which was positioned at suatabal distance from the plasma torch end as shown in Fig. 1. The films deposition was carried out for $5 \mathrm{~min}$ under conastant carrier gas flow rate and the substrate at room temprtar. The substrate moved on the $\mathrm{x}$ and $\mathrm{y}$ diraction mechanically for the purpose of obtaining a homogeneous films thickness a long the substrat area.To test the stability of the iodine doped films, these films are heat-treated at $373 \mathrm{~K}$ for $24 \mathrm{~h}$ in an oven and then the absorption spectrum is recorded. The Film thickness was measured using the optical interferometer method A double -beam UV-VIS-NIR 210A Spectrophotometer was used to measure the absorption of the Iodine-doped polythiophene and heat-treated polythiophene thin films which deposited at different iodine concentration in the range of 200-1200 nm. The background correction was taken for each scan. The absorption data with films thickness can be used to calculate absorption coefficients of the films at different Wave length, which 
have been used to determine the energy band gap $\mathrm{E}_{\mathrm{g}}$.

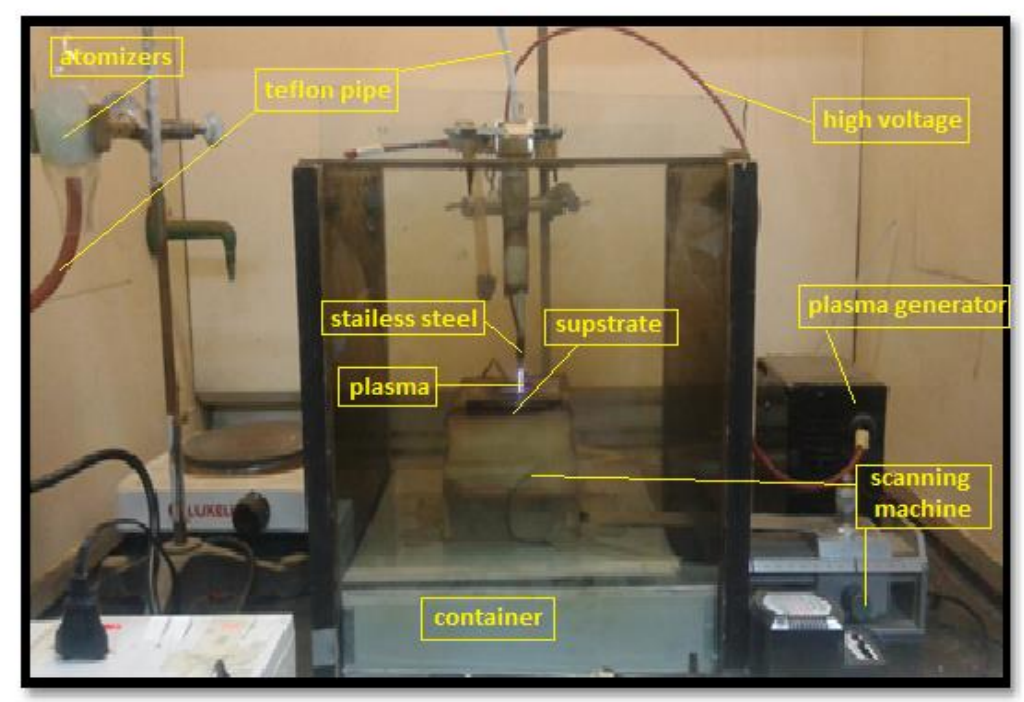

Fig. 1: The non-equilibrium atmospheric pressure plasma Iodine-doped polythiophene thin films praparation experimental set-up.

For FTIR spectroscopy poly thiophene is scraped from the glass substrates and is mixed with $\mathrm{KBr}$ before pelletizing. These pellets are then loaded into the sample holder of theFT-IR Shimadzu Co. FT-IR 8000 series Fourier transform, infrared spectrophotometer from wavelength range 400-4000 $\mathrm{cm}^{-1}$ under identical conditions. The morphological surface analysis is carried out employing an atomic force microscope (AA3000 Scanning Probe Microscope SPM, tip NSC35/AIBS) from Angstrom Advanced Inc. In order to study the structural properties, the structure is analyzed with a SHIMADZU 6000 X-ray diffractometer system which records the intensity as a function of Bragg's angle.The source of radiation is $\mathrm{Cu}-\mathrm{k \alpha}$ with wavelength $\lambda=1.5406 \AA$, current $30 \mathrm{~mA}$ and voltage $40 \mathrm{kV}$. The scanning angle $2 \theta$ is varied in the range of $10-80$ degree with aspeed of $5 \mathrm{deg} / \mathrm{min}$.

\section{Results and discussion}

\section{A. FTIR analysis:}

The FTIR spectra of thiophene as a monomer and Iodine-doped polythiophene thin films polymerized by plasma shown in Figs.2(a, b, c, d and e). The polythiophene spectrum, Fig. 2-b shows peaks at $484 \mathrm{~cm}^{-1}$ indicating that the ring is retained in the polymer[9]. The peak at $3468 \mathrm{~cm}^{-1}$ is due to $\mathrm{O}-\mathrm{H}$ stretch of water absorbed water .The peak at $3073-3108 \mathrm{~cm}^{-1}$ is due to $\mathrm{C}-\mathrm{H}$ stretch on double bonded carbon, and $2927 \mathrm{~cm}^{-1}$ is due to $\mathrm{C}-\mathrm{H}$ stretch on saturated carbon.

The FTIR spectrum for both monomer and plasma polymerized thiophene are comparable for their respective functional groups. 


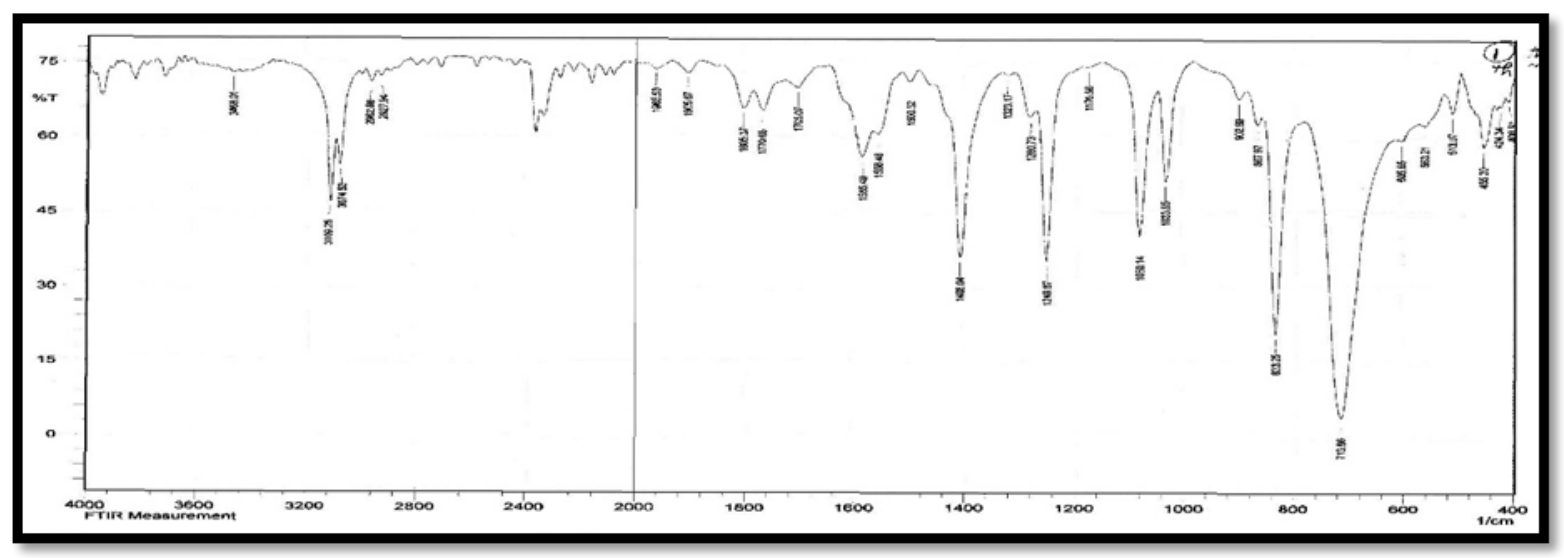

$\mathbf{a}$

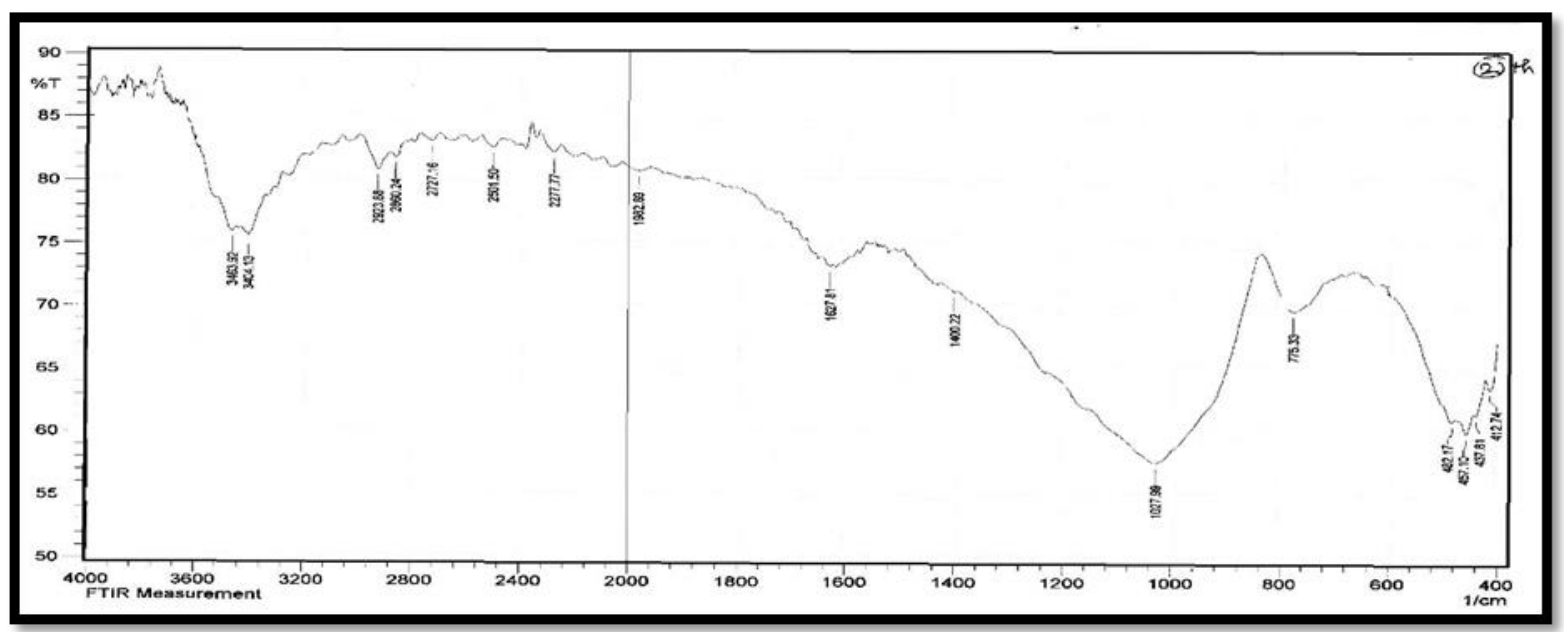

b

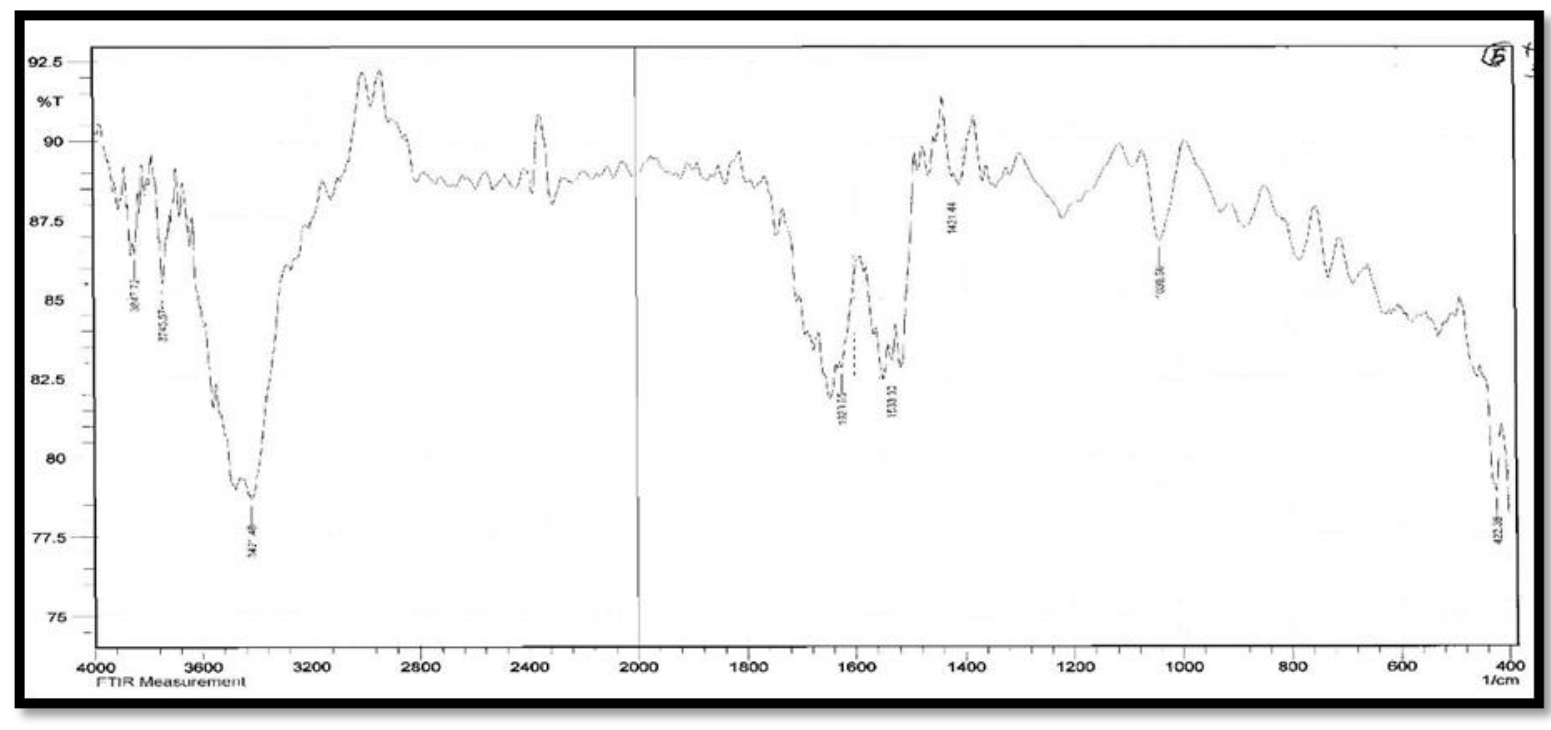




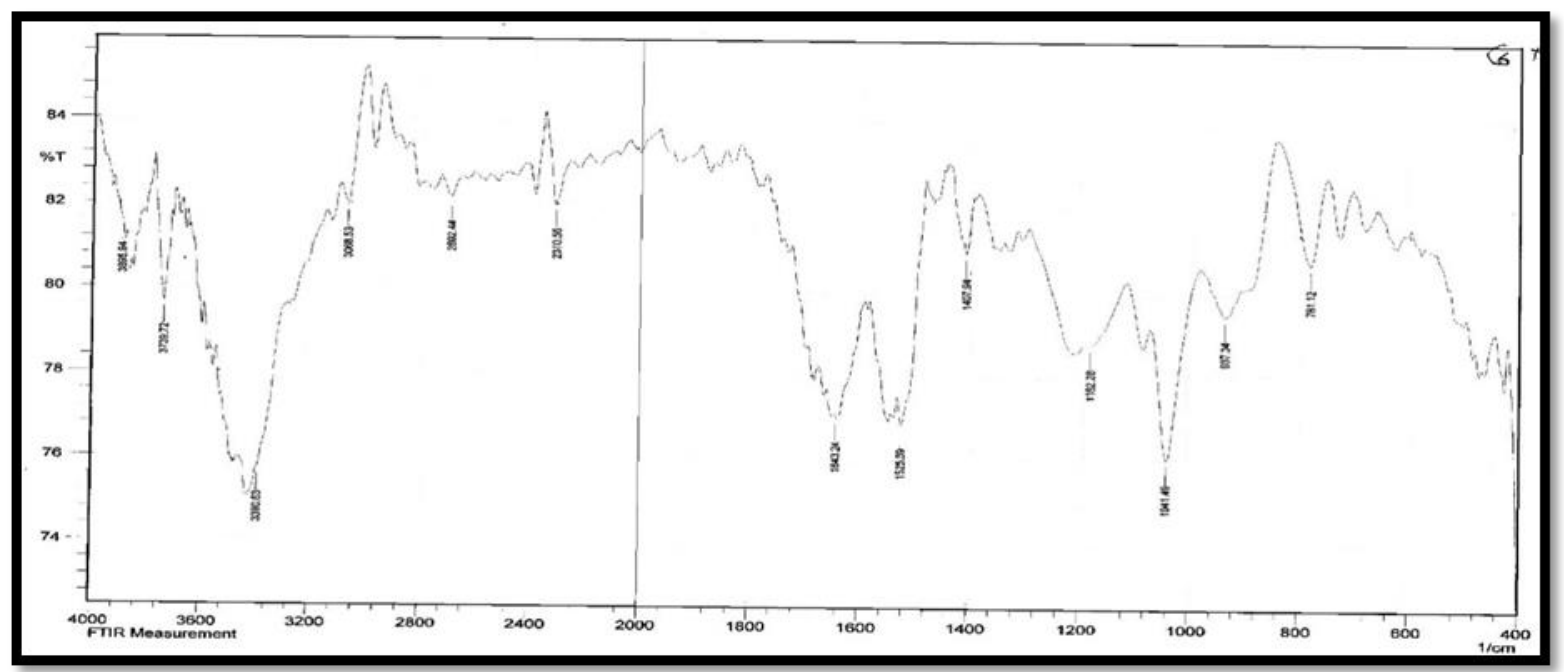

d

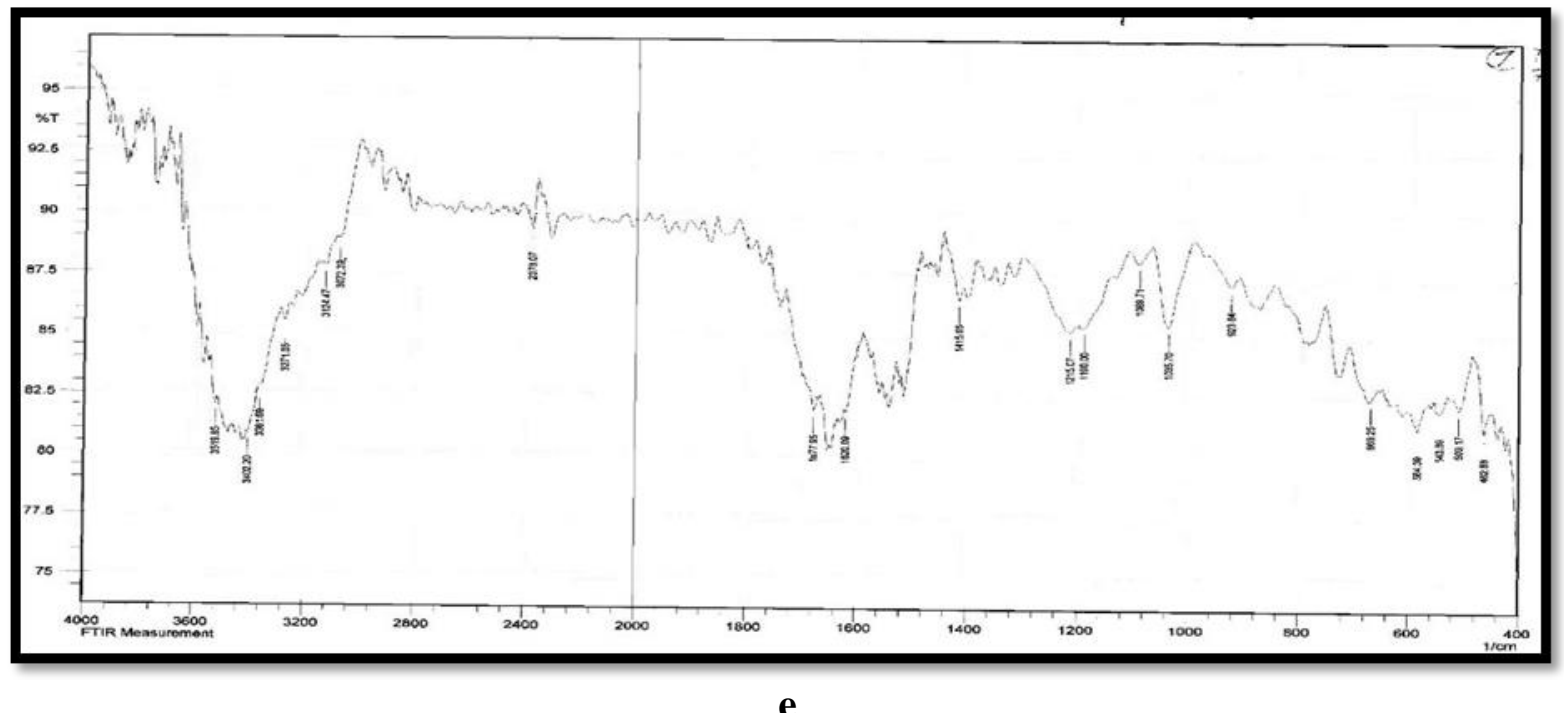

Fig.2: FTIR spectra a for thiophene monomer, b for polythiophene thin films without doping c for 3\% iodine doping $d$ for $5 \%$ iodine doping and e for $7 \%$ iodine doping.

The band assignments of the FTIR absorption bands for thiophene pure polythiophene, and iodine-doped polythiophene thin films are given in Table 1. It is clear from the table that there is a shift in $\mathrm{C}-\mathrm{H}$ stretching bands in the iodinedoped polythiophene. The $\mathrm{O}-\mathrm{H}$ stretch shifts towards high wave number. The shifts observed in $\mathrm{C}-\mathrm{H}$ bands indicate that the iodine atoms might be getting attached polythiophene [10]. The key bands corresponding to the polythiophene rings in the iodine-doped polythiophene are found to be shifted towards high wave number. This is an

indication that iodine doping causes a change in the structure of the plasma polymerized thiophene samples.

\section{B- UV-VIS absorption studies}

The photon absorption in many amorphous materials is found to obey the Tauc relation [10]:

$\alpha h v=B\left(h v-E_{\text {opt }}\right)^{\mathrm{n}}$ 
where $(\alpha)$ is the absorption coefficient, $h v$ is the photon energy, B constant and the index $\mathrm{n}$ is connected with the distribution of the density of states. The index $n=1 / 2$ corresponds to the direct allowed transition energy gap and $n=2$

Table 1: FTIR absorption bands for thiophene, pure polythiophene and iodine-doped polythiophene.

\begin{tabular}{|c|c|c|c|c|c|}
\hline Vibration & $\begin{array}{c}\text { Wavenumber } \\
\left(\mathrm{cm}^{-1}\right) \\
\text { mon-Thiophene }\end{array}$ & $\begin{array}{l}\text { Wavenumber } \\
\left(\mathrm{cm}^{-1}\right) \\
\text { polythiophene }\end{array}$ & $\begin{array}{c}\text { Iodine- doped } \\
\text { polythiophene } \\
\left(\mathrm{cm}^{-1}\right) 3 \%\end{array}$ & $\begin{array}{c}\text { Iodine- doped } \\
\text { polythiophene } \\
\left(\mathrm{cm}^{-1}\right) 5 \%\end{array}$ & $\begin{array}{c}\text { Iodine- doped } \\
\text { polythiophene } \\
\left(\mathrm{cm}^{-1}\right) 7 \%\end{array}$ \\
\hline $\begin{array}{c}\mathrm{O}-\mathrm{H} \text { stretch } \\
\text { absorbed water }\end{array}$ & 3468 & 3463 & 3407 & 3415 & ---------- \\
\hline $\begin{array}{l}\text { C-H stretch on } \\
\text { triple bonded } \\
\text { carbon }\end{array}$ & ------- & ----- & ----. & ----------- & 2369 \\
\hline $\begin{array}{l}\mathrm{C}-\mathrm{H} \text { stretch on } \\
\text { double bonded } \\
\text { carbon }\end{array}$ & $\begin{array}{l}3073 \\
3108\end{array}$ & -------- & 3062 & 3062 & $\begin{array}{l}3056 \\
3191\end{array}$ \\
\hline $\begin{array}{c}\text { C-H stretch on } \\
\text { saturated carbon }\end{array}$ & 2927 & 2923 & --------- & 2810 & 2812 \\
\hline $\mathrm{C} \equiv \mathrm{C}$ stretch & ---------- & 2277 & -------------- & 2310 & ------------- \\
\hline $\mathrm{C}=\mathrm{C}$ stretch & $\begin{array}{l}1408 \\
1558 \\
1590\end{array}$ & ${ }_{1682}^{1400}{ }^{1627}$ & 1519 & 1510 & $\begin{array}{l}1419 \\
1510\end{array}$ \\
\hline $\begin{array}{c}\mathrm{C}-\mathrm{H} \text { in plane } \\
\text { bends }\end{array}$ & $950-1250$ & 1027 & 1031 & $1043-1245$ & $1026-1222$ \\
\hline C-S stretch & 833 & 775 & 781 & 754 & 754 \\
\hline $\begin{array}{c}\text { C-H out of plane } \\
\text { bend }\end{array}$ & 710 & -------------- & 692 & 692 & 692 \\
\hline Ring deformation & Saturation & 484 & 460 & ---------- & 420 \\
\hline
\end{tabular}

represents the indirect allowed transition energy gap [11].

Fig.3 shows $(a h v)^{2}$ vs. photon energy graph of plasma polymerized thiophene in its pure and, iodine doped. It is seen from this figure and Table 2 that the iodine doping decreases the optical band gaps from $2.5 \mathrm{eV}$ for pure polythiophene to $2.05 \mathrm{eV}$ for polythiophene doped with $7 \%$ iodine the reduction in the optical band gap is probably due to the modification of the polymer structure.

Doping induces a structural ordering of the polymers due to the insert of the charged species. There are signatures supporting these changes in the FTIR and UV- VIS spectra. To test the stability of the iodine doped films, the films were heat-treated at $373 \mathrm{~K}$ for $24 \mathrm{~h}$ in an oven and then the absorption spectrum is recorded. It is found that these samples produce little change in the band gap, suggesting that the reduction in the band gap upon iodine doping is permanent and stable as shown in Fig. 4 and Table 2. 


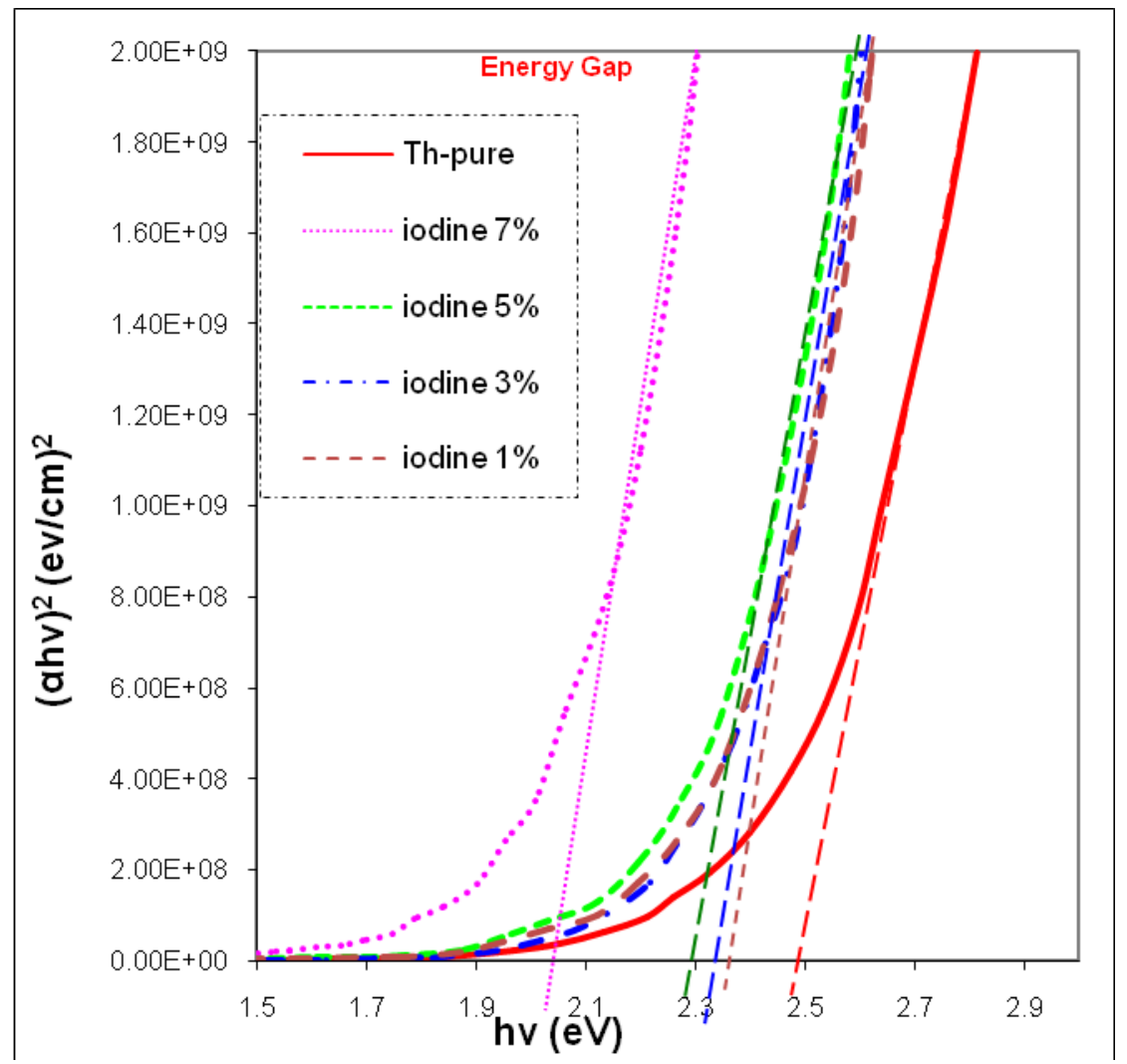

Fig. 3: (ahv $)^{2} v$ s. photon energy graph of plasma polymerized thiotpene thin films in its pure and iodine doped form.

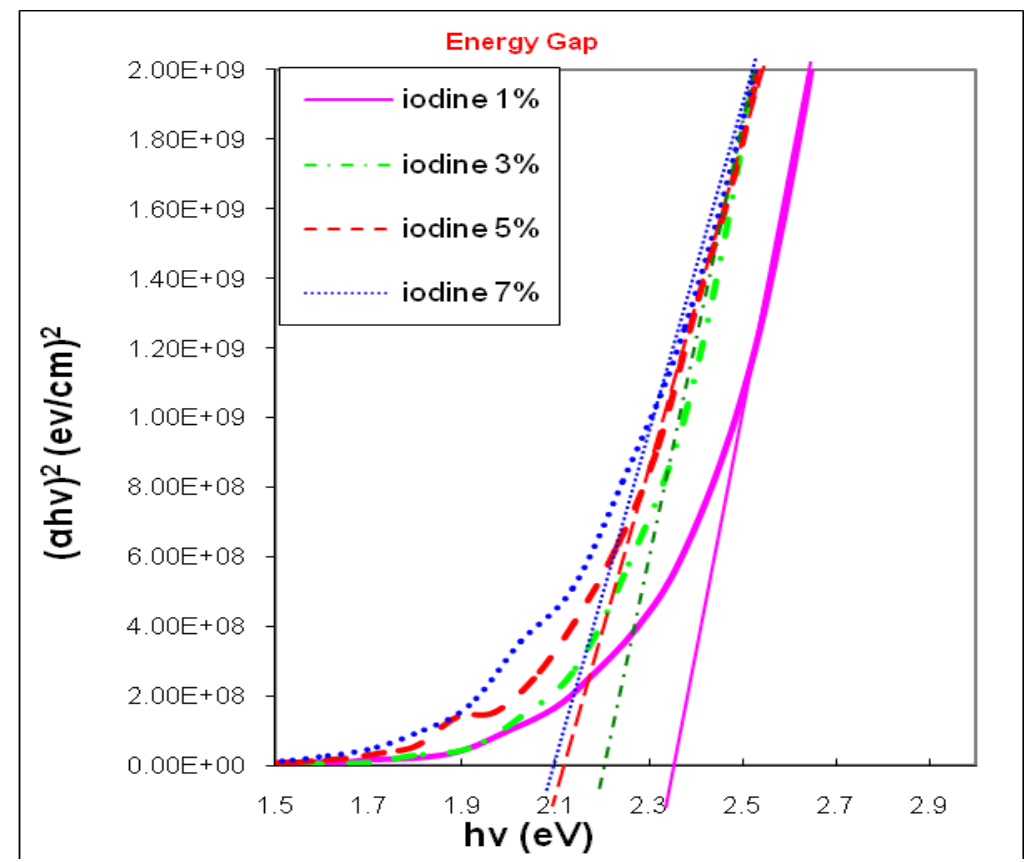

Fig.4: $(a h v)^{2}$ vs. Photon energy graph of heat-treated plasma polymerized iodine-doped thiotpene thin films. 
Table 2: Energy band gap of polythiophene iodine doped thin films as deposited and after heat-treated.

\begin{tabular}{|c|c|c|c|c|c|}
\hline Sample name & $\begin{array}{c}\text { Pure } \\
\text { Polythiophene }\end{array}$ & $\begin{array}{c}\text { 1\% Iodine } \\
\text { doped } \\
\text { polythiophene }\end{array}$ & $\begin{array}{c}\text { 3\%Iodine } \\
\text { doped } \\
\text { polythiophene }\end{array}$ & $\begin{array}{c}\text { 5\% Iodine doped } \\
\text { polythiophene }\end{array}$ & $\begin{array}{c}\text { 7\% Ioden doped } \\
\text { polythiophene }\end{array}$ \\
\hline $\begin{array}{c}\text { Direct allowed } \\
\text { transition energy } \\
\text { gap (eV) }\end{array}$ & 2.5 & 2.48 & 2.34 & 2.3 & 2.05 \\
\hline $\begin{array}{c}\text { Direct allowed } \\
\text { transition energy } \\
\text { gap heated at 373 K } \\
\text { for 24 h }\end{array}$ & 2.47 & 2.37 & 2.2 & 2.12 & 2.1 \\
\hline
\end{tabular}

\section{C-X-ray diffraction analysis}

X-ray diffraction pattern was employed to characterize the structure of the samples. Fig.5-a shows the pattern of the as-deposited pure polythiophene, while Fig.5-b represents the $7 \%$ iodine doped sample. It is clearly indicated that samples are of weak crystalline.

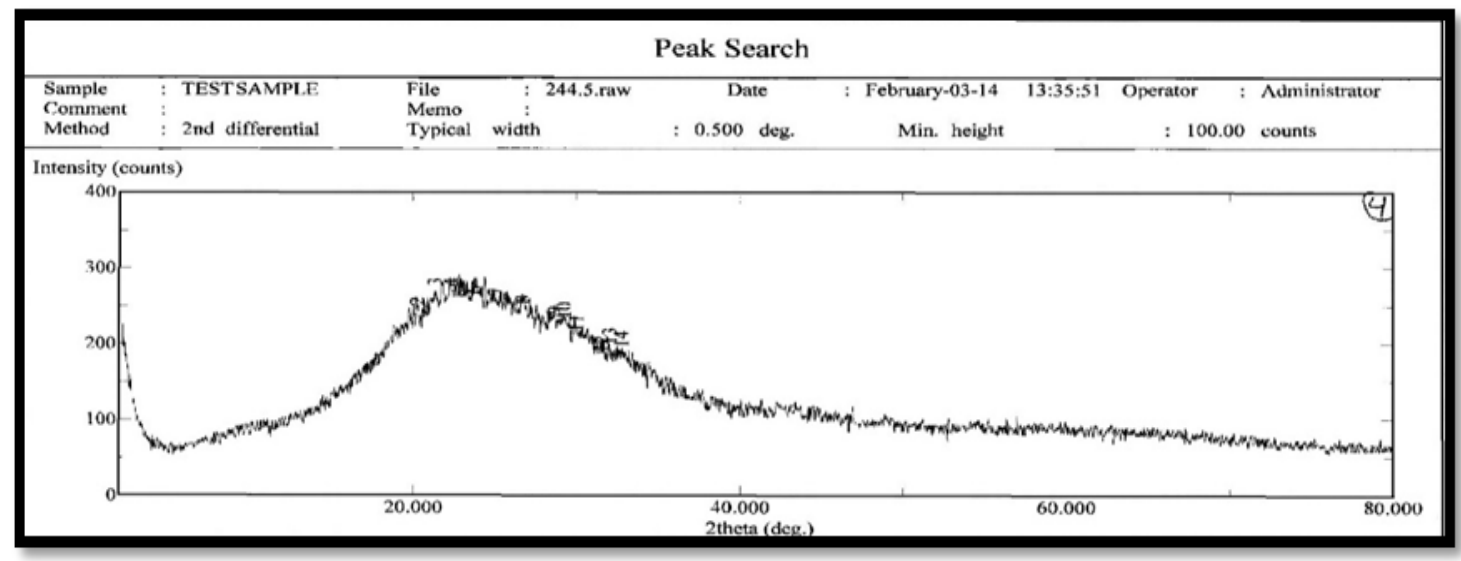

(a)

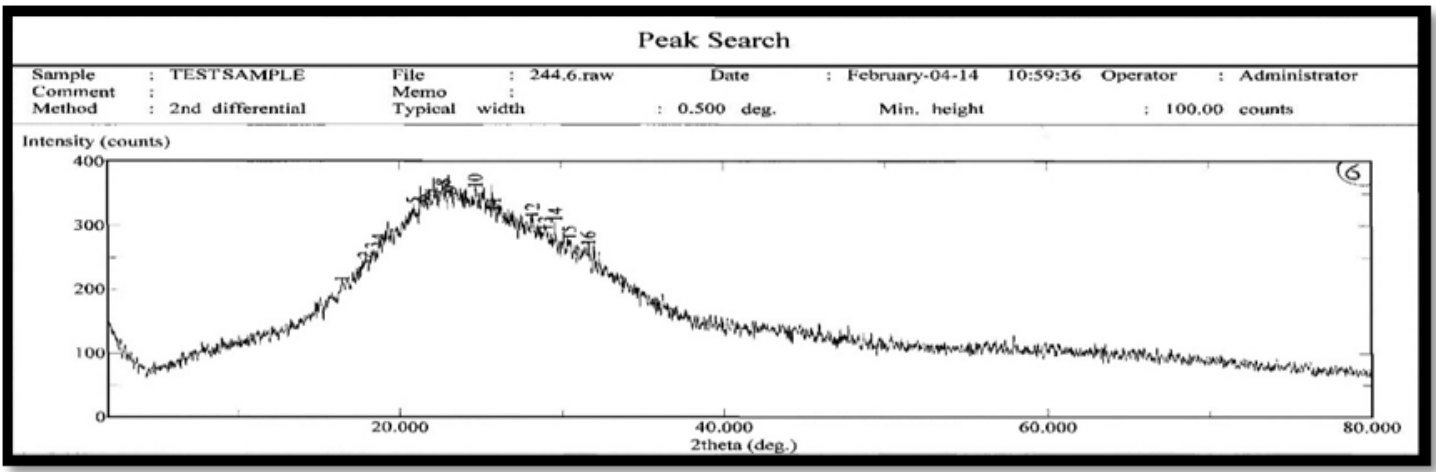

(b)

Fig. 5: XRD a) for pure polythiophene thin films and b) for iodine doped polythiophene thin films. 


\section{D- Surface morphology}

The surface morphology of pure polythiophene and 7\% iodine doped thin films were examined by AFM. The surface roughness of plasma polymerized pure polythiophene thin films was around 0.118 $\mathrm{nm}$ and for the iodine doped thin films $0.0939 \mathrm{~nm}$. The low surface roughness of plasma polymerized polythiophene confirms that the technique of plasma polymerization can be employed to produce extremely smooth films with very small surface roughness when compared to films prepared by other techniques. It is clear that the grains are uniformly distributed within the scanned area. Figs.6-a and b represent the 3-D and 2$\mathrm{D}$ images of the pure polythiophene thin films surface and Fig.6-c shows the granuality distribution chart. The average diameter of clusters is $87 \mathrm{~nm}$. Figs.7-a and b represent the 3-D and 2-D images of the 7\% iodine doped polythiophene thin films surface and Fig.7-c shows the granuality distribution chart. The average diameter of clusters was $79 \mathrm{~nm}$.

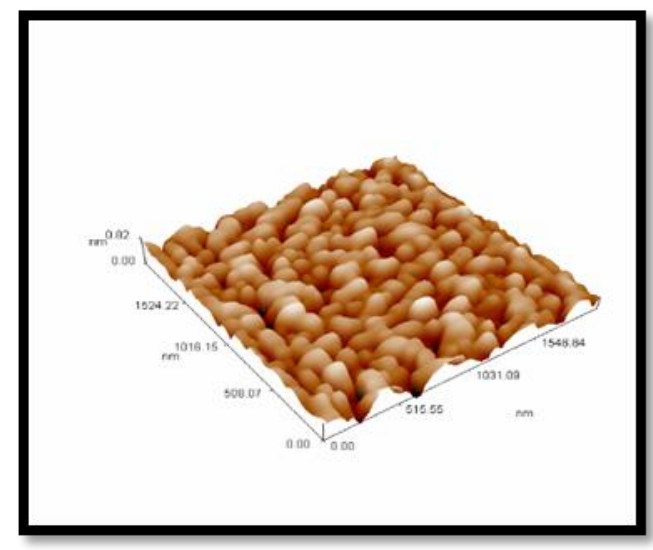

a

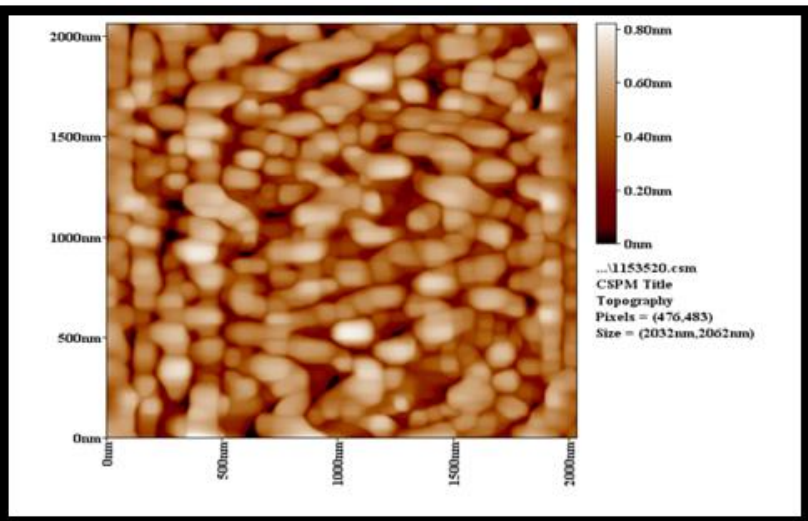

b

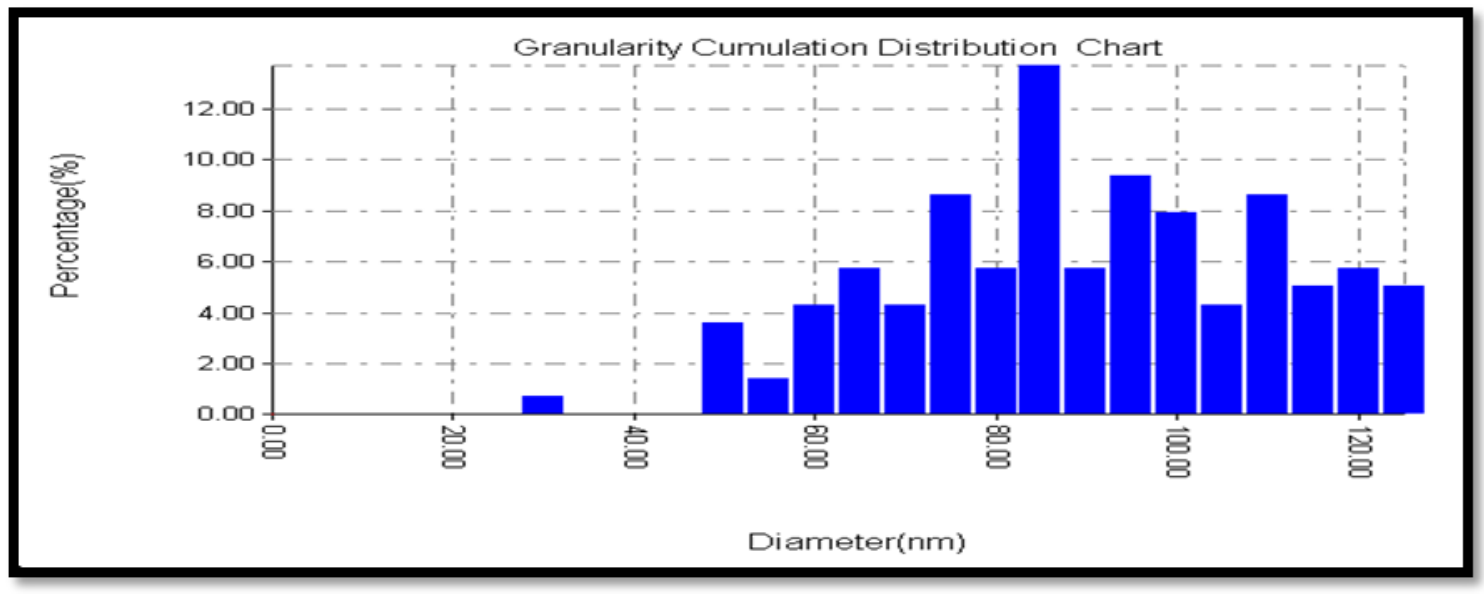

c

Fig. 6: AFM photographs of plasma polymerized pure thiophene thin films surface. a $3 D$ view b $2 D$ view and $c$ the granuality distribution chart. 


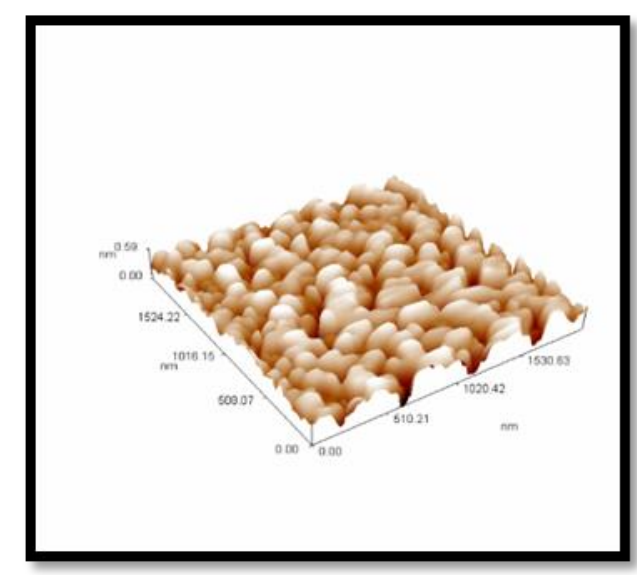

$\mathrm{a}$

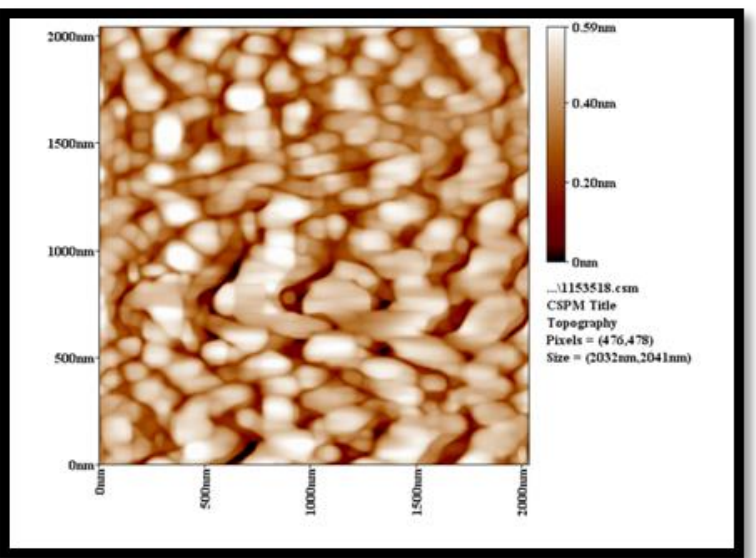

b

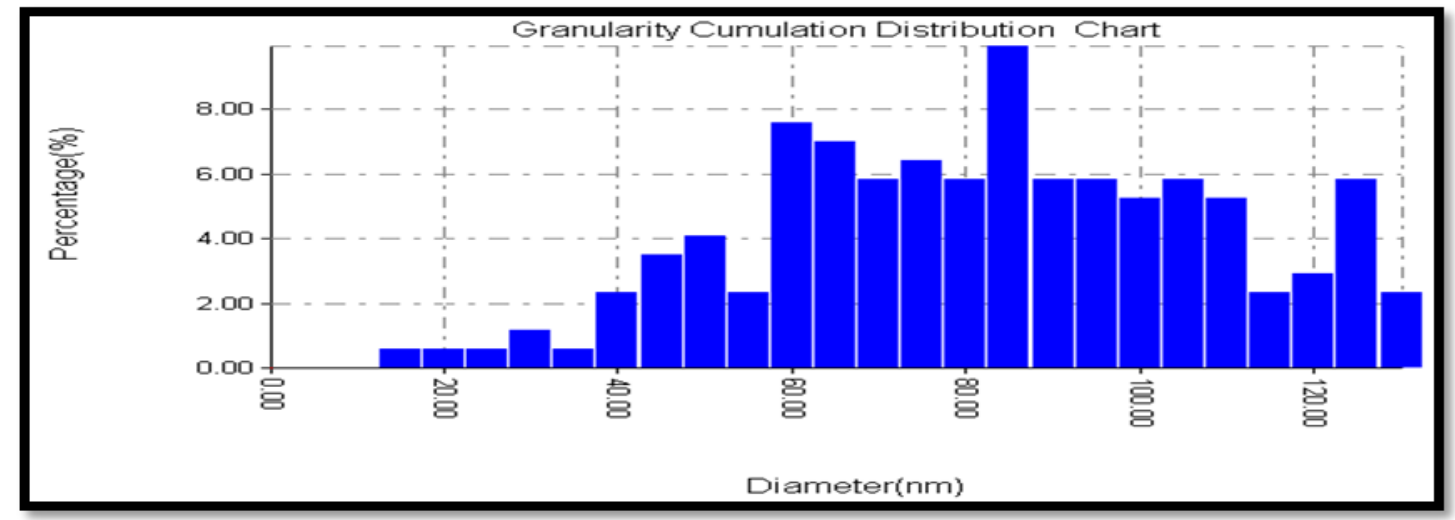

$\mathrm{c}$

Fig.7: AFM photographs of plasma polymerized 7\% iodine doped polythiophene thin films surface. $a 3 D$ view $b 2 D$ view and $c$ the granuality distribution chart.

\section{Conclusions}

The technique of plasma polymerization can be employed to produce extremely smooth films with very small surface roughness when compared to films prepared by other techniques. The grains are uniformly distributed within the scanning area. The insitu iodine doping Polythiophene thin films prepared by aerosol assisted plasma jet polymerization at atmospheric pressure decreases the optical band gaps and modifies the polymer structure. Heat-treated does not change the band gap. Hence, insitu method of doping is reliable and the change in the band gap is permanent.

\section{References}

[1] H. Biederman and D. Slavynska, Surf. Coat. Technol.125 (2000) 371.
[2]F. F. Shi, Surf. Coat.Technol. 82 (1996)1. [3] R. D. Agostino, "Plasma Deposition, Treatment and Etching of Polymers", Orlando, FL: Academic, 1990.

[4] K. J. Nagagawa, Appl. Polymer. Sci. 41(1990) 2049.

[5] Y. Koike, E. Nihei, N. Tanio and Y. Ohtsuka, Appl. Opt, 29 (1990) 2686.

[6] H. K. Chaudhar and D. S. Kelkar, Polymer International and Company, 1997.

[7] J. Tauc. "Optical Properties of Solids", ed A Ables, Amsterdam: North-Holland, 1970

[8] E. A. Davis and N. F. Mott, Phil. Mag. 22 (1970) 903.

[9]Hammad R. Humud, Thikra Kh. Obayes and Qusay A. Abbas, International Journal 
of Current Engineering and Technology, 4, 4 (2014) 2580-2584.

[10] J. I. Pankovem, "Optical Process" Englewood Cliffs, NJ Prentice-Hall, 1971
[11] A. B. M. Shah Jalal, S. Ahmed, A.H. Bhuiyan and M. Ibrahim, Thin Solid Films 288 (1996) 108. 